\title{
Preliminary exploration of the reform of Physics teaching involved in agriculture
}

\author{
E. J. Hao \\ JiLin University, Changchun, 130062, China \\ e-mail: haoerjuan0415@126.com
}

Key words: agricultural professional; college physics; teaching reform

\begin{abstract}
According to the actual situation of the students and course setting in faculty of agriculture, jilin university, we have carried out a series of reforms of college physics from the course offerings, optimize the teaching means and evaluation scheme and so on. Reform has made a preliminary result.
\end{abstract}

\section{Introduction}

University physics as a basic science is essential to every colleges and universities. However, in many majors involved agriculture, University physics is in a lower status and it develops slowly. Many students usually consider that physics associated with agriculture are small and physics is practical small to agriculture [1]. They have no interest and passion to learn it. Therefore, It's a immediate problem to reform curriculum of University Physics and Stimulate the students' interest who involved in agriculture in learning it and improve the quality of teaching for the teachers who teach physics courses. Our unit aim at reforming the condition of the students involved in agriculture without enthusiasm. From the perfect the curriculum setting to optimize teaching methods, we benefit information technology and simulation technology in experiment of college physics, after three years of practice has been to see results. I think twice before write this article. I Want to have a model function to brother institutions agricultural universities' physics curriculum.

\section{Improve university physics curriculum}

The division has dozens of professional and college physics as a public compulsory course, Over a period of time, Agronomy department of the university physics course Settings is too simple and the content of teaching is focus on theory. course emphasis too much on system and integrity. It Ignore the headquarters professional set of characteristics and the actual situation of the students, It Also lack of practical application so, it can't organic integration with information technology. Makes the student to the university physics learning interest is not high. According to this situation, we did a series of reforms.

First, we reform it from the selection of teaching materials. Faculty of agriculture open physics courses include mechanics, thermodynamics, electromagnetism and optics. But as a result of different agricultural professional student to study the different emphasis of college physics, for different professional, we selected the different teaching materials, With the depth and the difficulty is different and different teaching materials emphasis on different discipline, they are good enough to meet the different needs of the various professional.

Since the university physics courses of agronomy department in sophomore year. On the premise of learning college physics theory, so according to the actual situation of the division and introduction to specialties of elementary school in the summer vacation period we opened a series of electives relating to the college physics. As we support classes, Such as 《the physical and health》, 《journal of mathematical physics》, 《physics and the world》《demonstration experiment and scientific and technological innovation》 and so on. These elective courses set up perfect the university physics curriculum from different angles, meet the needs of the students. Stimulate the students' interest in physics learning. 


\section{Optimize teaching methods and means}

We change the way that teachers give lessons to students who are passive to accept knowledge. Teachers should pay more attention to the physical thoughts and show the laws of physics by doing experiments and reduce the specific derivation at the same time. Use the $1+1+1$ teaching mode. It is when finish the theoretical lessons of each chapters, we should follow the last seminar on this section and do the experiment related to this chapter.

Because today is an information society, the traditional teaching methods and means far can not satisfy the needs of students[2], In lessons of theory we use the multimedia teaching, made up for the inadequacy of traditional teaching. Beautiful pictures and videos in the multimedia courseware can performance the content which blackboard and chalk are unable to performance to help students enhance understanding and memory. In order to optimize teaching method, we introduce the demonstration experiment into the classrooms. Demonstration experiment has a unique charm and function is unmatched by traditional teaching methods. Such as: Demonstration experiment can effectively develop the students' ability of observation and practice and can effectively inspire the minds of students and Cultivate their spirit of exploration. In theoretical classes, teachers and students prove the validity of the theory of physics together through demonstration experiment to make the students feel the fun of learning physics. We can know the changes of students in physical knowledge by introducing demonstration experiment. That is if you do the demonstration experiment you will remember the knowledge if you don't do the demonstration you forget knowledge soon.

We have also developed university physics network curriculum at present it is an effective supplement for the classroom teaching. Network courses can achieve resource sharing, resources of sharing including electronic materials, multimedia courseware, etc. It also equipped with network answering, strengthen the exchange between teachers and students, it also have the test online to let the students pass the test to deepen understanding and mastering of knowledge. Net work curriculum can achieve the optimization and integration of Classroom instruction and network self-study.

In order to understand students' mastery of knowledge, when each chapter teaching is completed, we will be the last seminar. The teacher will take 10 minutes of the seminar to sort out the heavy difficult point of this chapter, then give 2-3 questions to students and make the students be group discussions and the discussion time is about 30 minutes, then change roles between teachers and students to encourage students to solve more than one solution, a clever solution[2-6]. It is not only enhances the thought and study methods of communication between students but also enhance the understanding of knowledge gradually, the students from the initial discussion is not open up to they can targeted discussion, classroom atmosphere become relaxed and happy and the effect is pretty good.

We will open a physical experiment related to this chapter then. Because of the ideological understanding bias for a long time makes the university physics experiment curriculum to carry out the effect is not very ideal and the students is not very interesting to have it. Students are still in a state of "chaos", In addition, the current experiment is set on some of the content is mostly to test theory principle, the phenomenon, the experiment set of lack of creativity, so as to make the experiment content is not deep, dragonfly water, such a bad cycle makes the students gradually lose interest in college physics experiments after the experiment.

In order to make physics experiment teaching better. We introduce the simulation technology university physical experiment courses, Physical simulation experiment simulate the physical experiment environment through the computer and related software [7]. Simulation experiment system can build a virtual experiment environment and can realistically simulate the whole process of operation which students carry on, can display the measured results soon, can provide a variety of experimental methods, can implement a more flexible operation. Physical simulation experiment can put the theory teaching and experiment teaching organically integrated to overcome the past two teaching ways entirely separation condition. Students will have a overall understanding for the experimental principle, instrument structure and debugging techniques, etc through simulation 
technology. Physical experiment is easy to operate. It improves the quality and efficiency of experiment teaching greatly and stimulate the learning enthusiasm of the students of experiment teaching.

We construct the university physics experiment hierarchical module of the new curriculum system in addition. In fundamental experiment, comprehensive experiment, design and improve experiments for pilot module structure, introduce the simulation technology and virtual reality technology into college physical experiment courses to strengthen the construction of demonstration laboratory, broaden students' horizons, contact the latest experiment of the method of training, change the status of the physics experiment with modern science and technology progress[8-10].

In view of the different levels of experimental teacher participation are different, in basic experiments, teachers give a present topic, and they don't intervene the students' experimental conclusion after student grouping experiments and analyze the experimental results. In Comprehensive experiments, teacher give a topic, first of all, students in group discussion to find out suitable experiment scheme then do experiments and come to conclusions. In design and improve the experiments, teacher give a topic then students group discussion firstly then give experimental scheme, teachers and students discuss the relative merits and feasibility experiment scheme together. After discussion, Students carry on the improvement and optimization, and then began to specific operation according to the discussion about their program. Adopting such teaching process, it can show the experimental difficulties clearly and can exercise the students' ability of expression and summarizing ability. It is also cultivate the students' basic skills, cultivate the students' cooperation spirit, and stimulate the students' interest and motivation for physical experiment.

\section{Improve the method of teaching evaluation}

Students' physical results basically decided by the final examination paper grades before the university physics teaching reform,. In order to fully reflect the students' comprehensive quality and ability, our assessment methods of university physics is carried on the reform. Final grade is made up of three parts, the final question paper grades (50\%), peacetime grades (15\%), Experiment results (35\%). Grades are mainly completed by a student's work and participation in seminars. Experiment result is given by the experiment teacher according to the Students of experiment scheme and step put forward, and experiment of the innovative factors, students are asked to write an experimental summary of this term final. The reformation can fully embody the level of the students, stimulate the students' interest in learning physics.

\section{Regular physics lecture should be hold}

In order to make students fully experience the physical charm, to stimulate interest in learning physics. We also open physics seminar on a regular basis combine professional setting and the actual needs of students. Such as: 1) laser application in agriculture, 2) electromagnetism application in agriculture3) physical and employment, etc. The opening of these lectures attracted related specialized student to listen to. It also allows students to further understand the contact with the professional physics and how to use physical knowledge to learn this professional knowledge.

\section{Conclusion}

Physics is the most mature of a natural science, we not only can learn physics knowledge but also can learn natural science in research methods, test methods, etc which can be reference to other subjects. Therefore, in agricultural professional teaching of college physics, we relatively ensures the physics teaching content relatively complete, Students can improve themselves and learn to find problems and practice problem solving skills, understand the application of physics knowledge in this major. According to the physics course teaching experience not majored in physics Theory teaching hours shall not be less than 100 hours advisable, But Agronomy department of physics 
course set period is only 72 hours, at this point, we should further improve in the future. Agricultural physics curriculum teaching research project involves all aspects, There are many problems to be engaged in agricultural university physics teaching, In terms of agricultural professional college physics courses reform, we are groping forward, I hope we will be better and better.

\section{Acknowledgment}

This work has been supported by Public education center of Jilin University. Dr. Li has given some useful suggestions.

\section{References}

[1] E J Hao,T Li. "Practice and Analysis ofTeaching Reform in University Physics Experiment in Agricultural School”.[J]. Journal of Educational Institute Of Jilin Province. 2011, 27(8) :55-57.

[2] Chen Han-jun. Exploration and Practice of Innovative Physics Demo Laboratory Construction.[J] Research and Exploration in Laboratory, 2011,30(6):185-87.

[3] Dong Hai-kuan, FE I Ying. Discussion on teaching of college physics simulated experiment. [J]Journal of Bohai University (Natural Science Edit ion).2008, 29(1):80-82.

[4] Su Ya-feng, XU Zhong-f eng. A discussion of Chinese college physics teaching reform upon reviewing UIUC college physics teaching programs. [J]. College Physics, 2011, 30(5):48-51.

[5] Zhou Feng-fan, WANG Hao-cheng. The value reconstruction of university physics demonstration experiments. [J] .College Physics, 2011, 30(5):46-50.

[6] Liu Shu-e, SHI Jing-zhong, SUN Lei. Practice and Thinking about the Construction of College Physics Demo Lab. [J] Research and Exploration in Laboratory, 2011, 30(6):192-194.

[7] Xiao Xiang-pin, CHEN Jian-jun, WANG Yun, WANG Xiao-yin. Innovative Research on the Practice Teaching System of Forestry University Science Courses. [J]. Research and Exploration in Laboratory, 2011, 30(6):114-116.

[8] Zhang Jun-ling, Study of the Creative Design Method and Some Applied,Cases in College Physics Experiment Physical experiment of college.2011,24: 93-96.

[9] Ma J ia-ning, L I Hua. Bilingua lteaching research on quantum mechanics [J] .College Physics, 2009, 29:47-50.

[10] Wang Wenqi, Peng Zhensheng The problems and the thoughts about College, Physics Teaching for Non-physics majors.[J].Journal of Chuzhou university,2009,.11:102-104. 